Arkivoc

Free to Authors and Readers
A Platinum Open Access Journal for Organic Chemistry
Paper

Arkivoc 2021, part vi, $120-130$

\title{
Mixed matrix membranes derived from a spirobifluorene polymer of intrinsic microporosity and polyphenylene networks for the separation of toluene from dimethyl sulfoxide
}

Richard A. Kirk, ${ }^{a}$ Chunchun Ye, ${ }^{b}$ Andrew B. Foster, ${ }^{a}$ Alexey V. Volkov, ${ }^{c}$ Neil B. McKeown, ${ }^{* b}$ and Peter M. Budd*a

${ }^{a}$ Department of Chemistry, University of Manchester, Manchester M13 9PL, UK

${ }^{b}$ EastChem, School of Chemistry, University of Edinburgh, David Brewster Road, Edinburgh EH9 3FJ, UK

'A.V. Topchiev Institute of Petrochemical Synthesis, 29 Leninsky Av., Moscow 119991, Russian Federation

Email: Peter.Budd@manchester.ac.uk; neil.mckeown@ed.ac.uk

Dedicated to Professor Philip Hodge, recognising his contributions to polymer chemistry over 45 years

Received 06-11-2021

Accepted Manuscript 07-14-2021

Published on line $07-22-2021$

\section{Abstract}

A spirobifluorene polymer of intrinsic microporosity (PIM-SBF) and polyphenylene networks based on triphenylbenzene (TPB), hexaphenylbenzene (HPB) and octaphenylquinquephenyl (OPQ) were synthesised and characterized. Uncrosslinked membranes of PIM-SBF proved suitable for the separation of a toluene/DMSO mixture (77:23 volume ratio) by pervaporation at $65^{\circ} \mathrm{C}$, giving a separation factor of 3.9 and a flux of $2.0 \mathrm{~kg} \mathrm{~m}$ $\mathrm{h}^{-1}$. The addition of 5 wt\% HPB network enhanced the separation factor, while OPQ and TPB networks increased the flux that could be achieved.
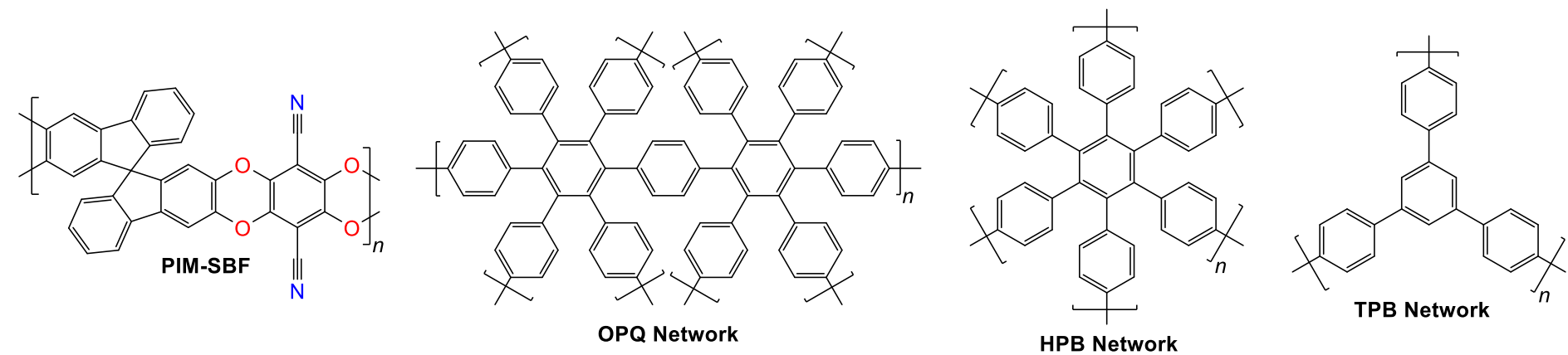

Keywords: Polymer of Intrinsic microporosity, hypercrosslinked polymer, membrane, pervaporation 


\section{Introduction}

The first solution-processable polymers of intrinsic microporosity (PIMs), which possess high free volume in the glassy state due to inefficient packing of their rigid, contorted macromolecular backbones, were reported in 2004. ${ }^{1}$ PIMs have since been the focus of much research activity, especially for applications as membrane materials. ${ }^{2,3}$ The prototypical PIM-1 (1, Figure 1$)$ is synthesised by a step-growth polymerization involving double aromatic nucleophilic substitution reactions between $5,5^{\prime}, 6,6^{\prime}$-tetrahydroxy-3,3,3',3'-tetramethyl-1,1'spirobisindane and tetrafluoroterephthalonitrile. The first membrane application of PIM-1 to be investigated was the pervaporative removal of phenol from aqueous solution. ${ }^{4}$ In the pervaporation process, the feed is a liquid mixture and a vacuum is applied to remove permeate as a vapour. ${ }^{5}$ Recently, we have been exploring the use of PIM-based membranes for the recovery of aromatic hydrocarbons from polar solvents. ${ }^{6}$ Benzene, toluene and xylenes, which are important feedstocks for the chemical industry, are commonly removed from other products in a catalytic reformate by an extractive distillation with a polar solvent. Regeneration of the solvent is typically carried out by distillation with steam at high temperature, and there is potential for large energy savings through the use of membrane processes.

PIM-1 has high affinity for aromatic hydrocarbons, but partial dissolution of a PIM-1 membrane may occur under the conditions of use, unless the membrane is subjected to a post-fabrication crosslinking process. ${ }^{7,8}$ In the present work, we investigated an alternative PIM, spirobifluorene-PIM (PIM-SBF, 2, Figure 1), in which benzene units are fused to the spirocyclic centre. ${ }^{9}$ Functionalised variants of PIM-SBF have previously been investigated as gas separation membranes ${ }^{10}$ and as adsorbents for the removal of textile dyes from wastewater. ${ }^{11}$ In the present work, uncrosslinked membranes of PIM-SBF proved stable for pervaporation of a mixture of toluene and dimethyl sulfoxide (DMSO).
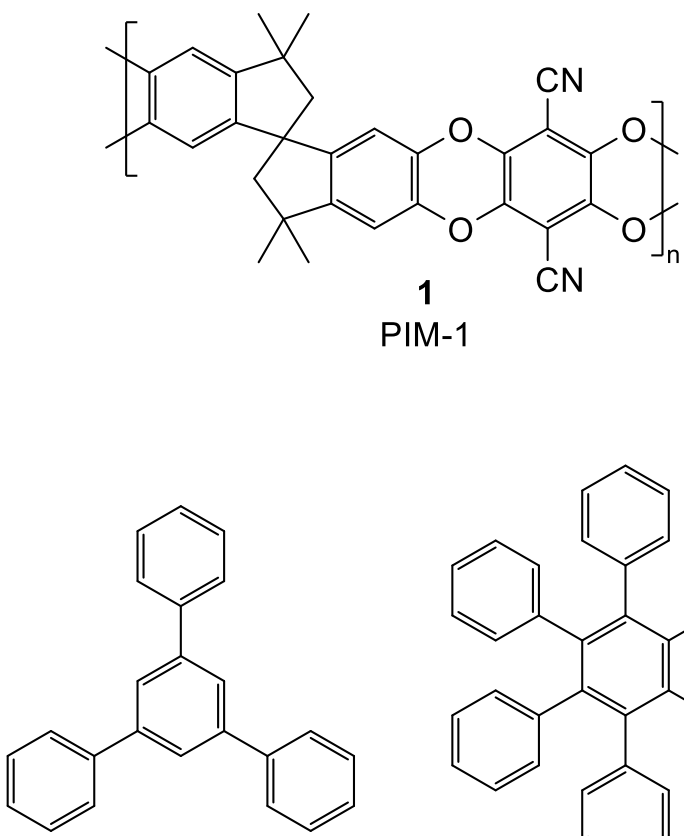

3

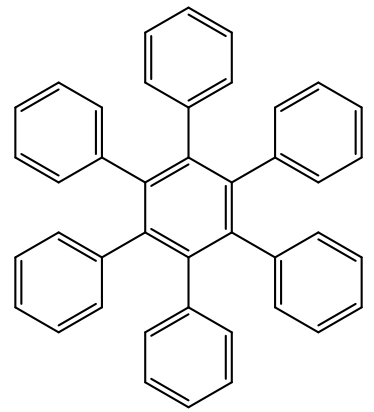

4

HPB
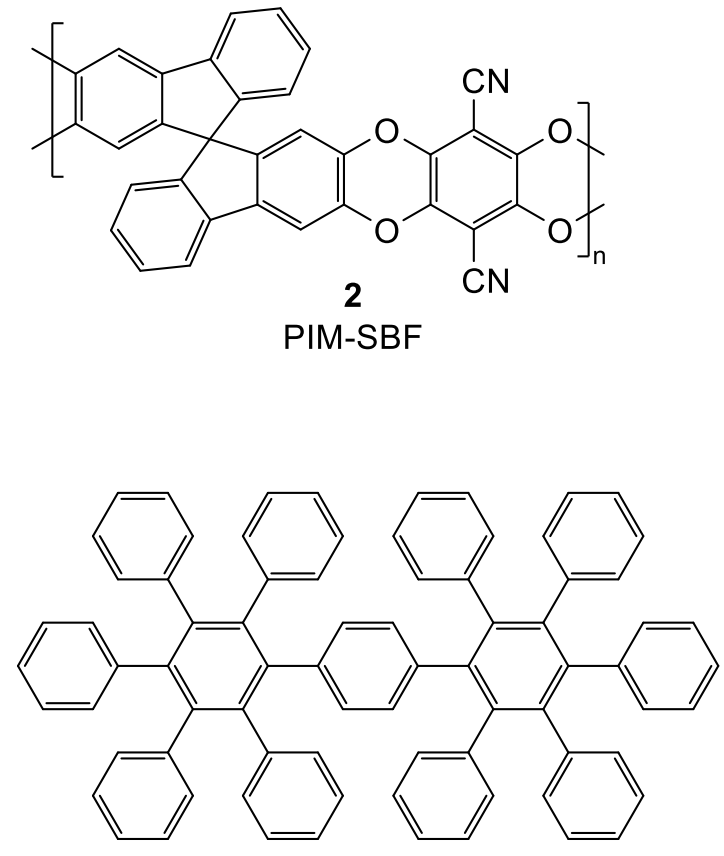

5

$\mathrm{OPQ}$

Figure 1. Structures of polymers of intrinsic microporosity PIM-1 (1) and PIM-SBF (2) and monomers TPB (3), HPB (4) and OPQ (5) used to form polyphenylene networks. 
In order to tailor the separation factor and flux of permeate, mixed matrix membranes (MMMs) were prepared with PIM-SBF as the soluble polymer matrix incorporating three insoluble hypercrosslinked polyphenylene networks. The networks were prepared from triphenylbenzene (TPB, 3), hexaphenylbenzene $(\mathrm{HPB}, 4)$ and octaphenylquinquephenyl $(\mathrm{OPQ}, 5)$ (structures shown in Figure 1) using $\mathrm{AlCl}_{3}$ as a Friedel-Crafts catalyst and dichloromethane (DCM) as solvent. ${ }^{12}$

\section{Results and Discussion}

PIM-SBF was prepared from the aromatic nucleophilic substitution reaction between $2,2^{\prime}, 3,3^{\prime}$-tetrahydroxy9,9'-spirobifluorene and 2,3,5,6-tetrafluoroterephthalonitrile following a previously reported procedure (Scheme 1). ${ }^{9}$ The resulting PIM-SBF polymer is freely soluble in chloroform, showing number-average molecular weight $\left(M_{\mathrm{n}}\right)$ of $66,500 \mathrm{~g} \mathrm{~mol}^{-1}$ and weight-average molecular weight $\left(M_{\mathrm{w}}\right)$ of $170,000 \mathrm{~g} \mathrm{~mol}^{-1}$, relative to polystyrene standard samples, measured by gel permeation chromatography (GPC). Analysis of the $\mathrm{N}_{2}$ adsorption isotherm suggests that powdered PIM-SBF possesses microporosity (pore size $<2 \mathrm{~nm}$ as defined by IUPAC) ${ }^{13}$ and gives a Brunauer-Emmett-Teller (BET) surface area of $869 \mathrm{~m}^{2} \mathrm{~g}^{-1}$. Mechanically robust and self-standing PIM-SBF films can be fabricated by simple solvent casting from chloroform solution followed by slow evaporation.

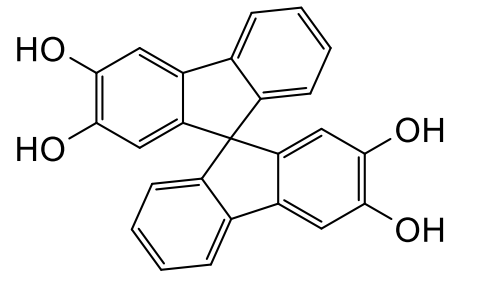<smiles>N#Cc1c(F)c(F)c(C#N)c(F)c1F</smiles>

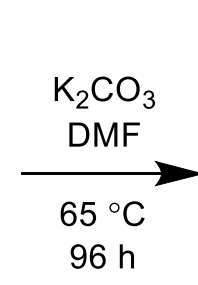

$96 \mathrm{~h}$

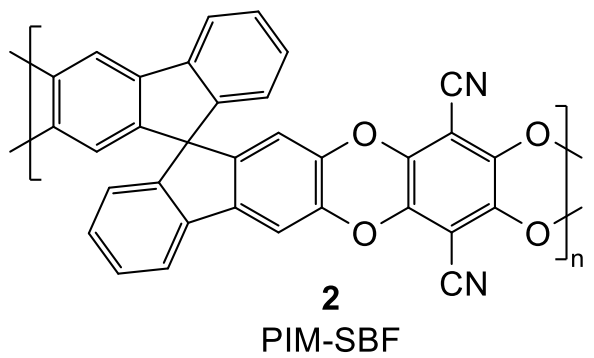

PIM-SBF

Scheme 1. Synthesis of PIM-SBF.

Networks were synthesised from TPB (Scheme 2), HPB (Scheme 3) and OPQ (Scheme 4). In the case of the $\mathrm{HPB}^{14}$ and $\mathrm{OPQ}^{15}$ hydrocarbons, they were prepared using methodologies adapted from previously reported work ${ }^{14-16}$ in which either benzil or bisbenzil undergo an aldol condensation with 1,3-diphenylpropan2-one to prepare the intermediary cyclopentadienone. This then undergoes a Diels-Alder reaction with diphenylacetylene to give the desired hydrocarbon. The polyphenylene networks were then prepared using a Friedel-Crafts reaction as mentioned above. The polyphenylene networks exhibited high BET surface areas, $>2,000 \mathrm{~m}^{2} \mathrm{~g}^{-1}$ for the TPB and OPQ networks, and $\mathrm{ca} .1,700 \mathrm{~m}^{2} \mathrm{~g}^{-1}$ for the HPB network. MMMs were prepared with 5 wt\% of network in PIM-SBF. 

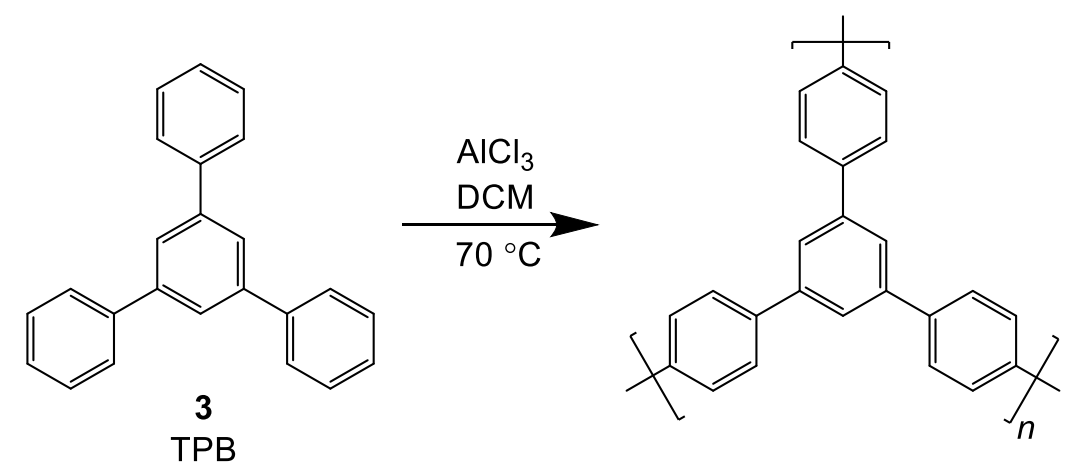

Scheme 2. Synthesis of TPB network polymer.

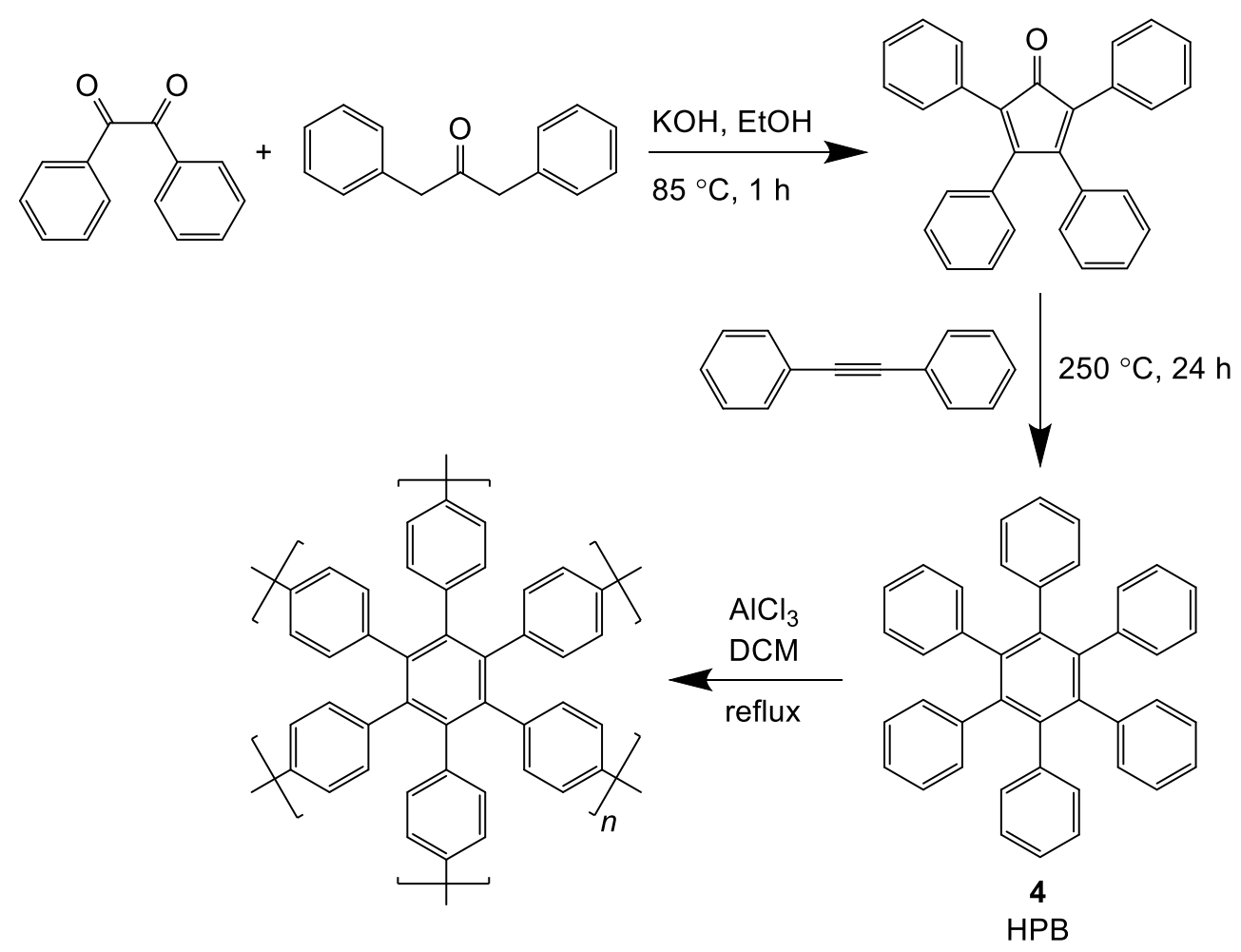

Scheme 3. Synthesis of HPB network polymer. 

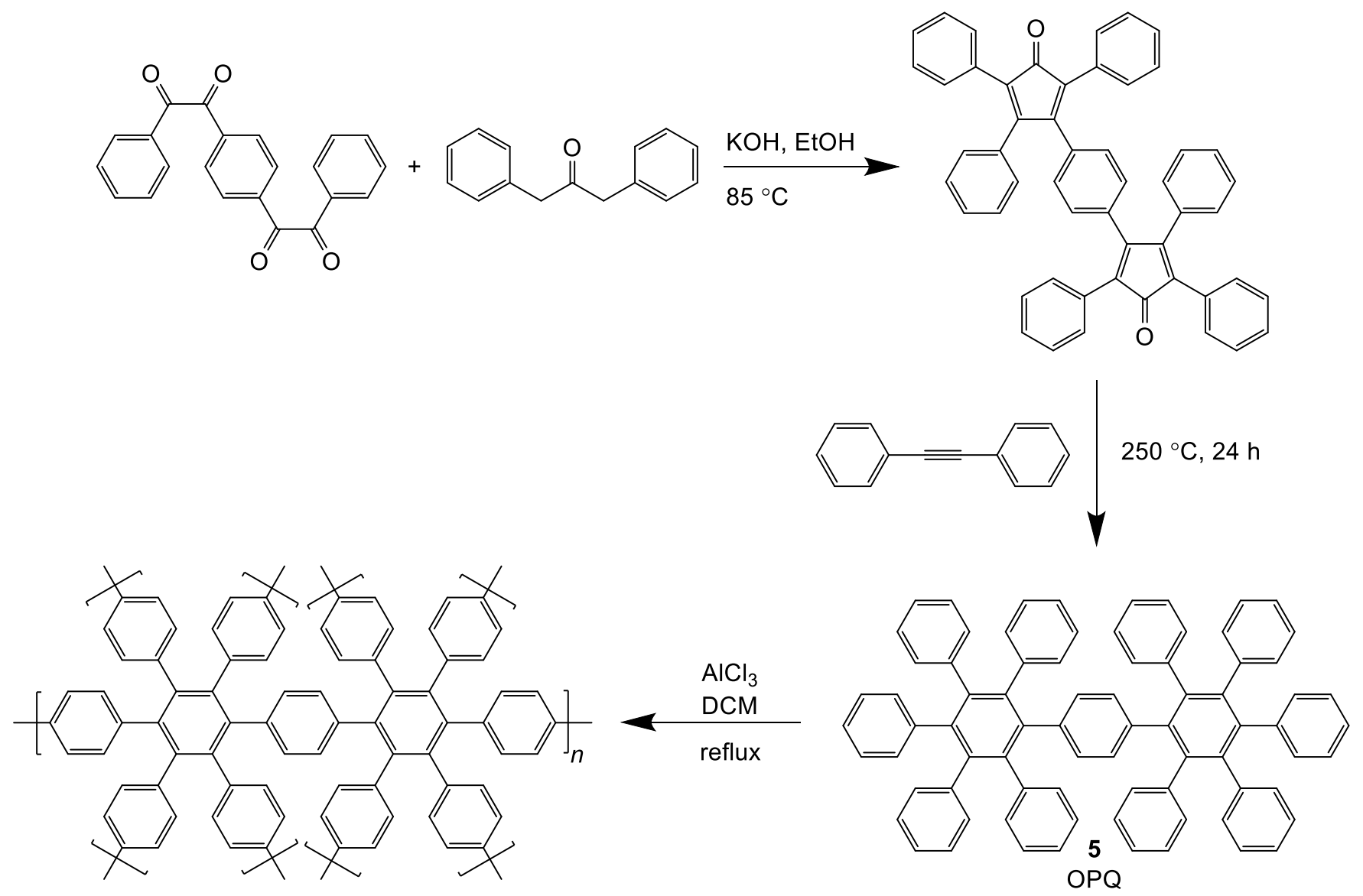

Scheme 4. Synthesis of OPQ network polymer.

Any membrane process requires an appropriate balance between the ability to separate the components of a mixture and the productivity of the membrane. In pervaporation studies of binary mixtures, it is common to express separating ability in terms of a separation factor, $\beta=\left[\left(Y_{i} / Y_{j}\right) /\left(X_{i} / X_{j}\right)\right]$, where $Y_{i} / Y_{j}$ is the weight or molar ratio of the components in the permeate and $X_{i} / X_{j}$ is the corresponding ratio in the feed. In the present work, component $i$ is toluene and component $j$ is DMSO. The productivity of the membrane may be expressed in terms of flux (amount of permeate per membrane area per unit time). As there is generally a trade-off between separation factor and flux, the overall performance of a membrane is indicated by a pervaporation separation index, PSI $=J_{\text {total }}(\beta-1)$, where $J_{\text {total }}$ is the total flux of both components. The PSI is zero if there is either no flux or no separation. 


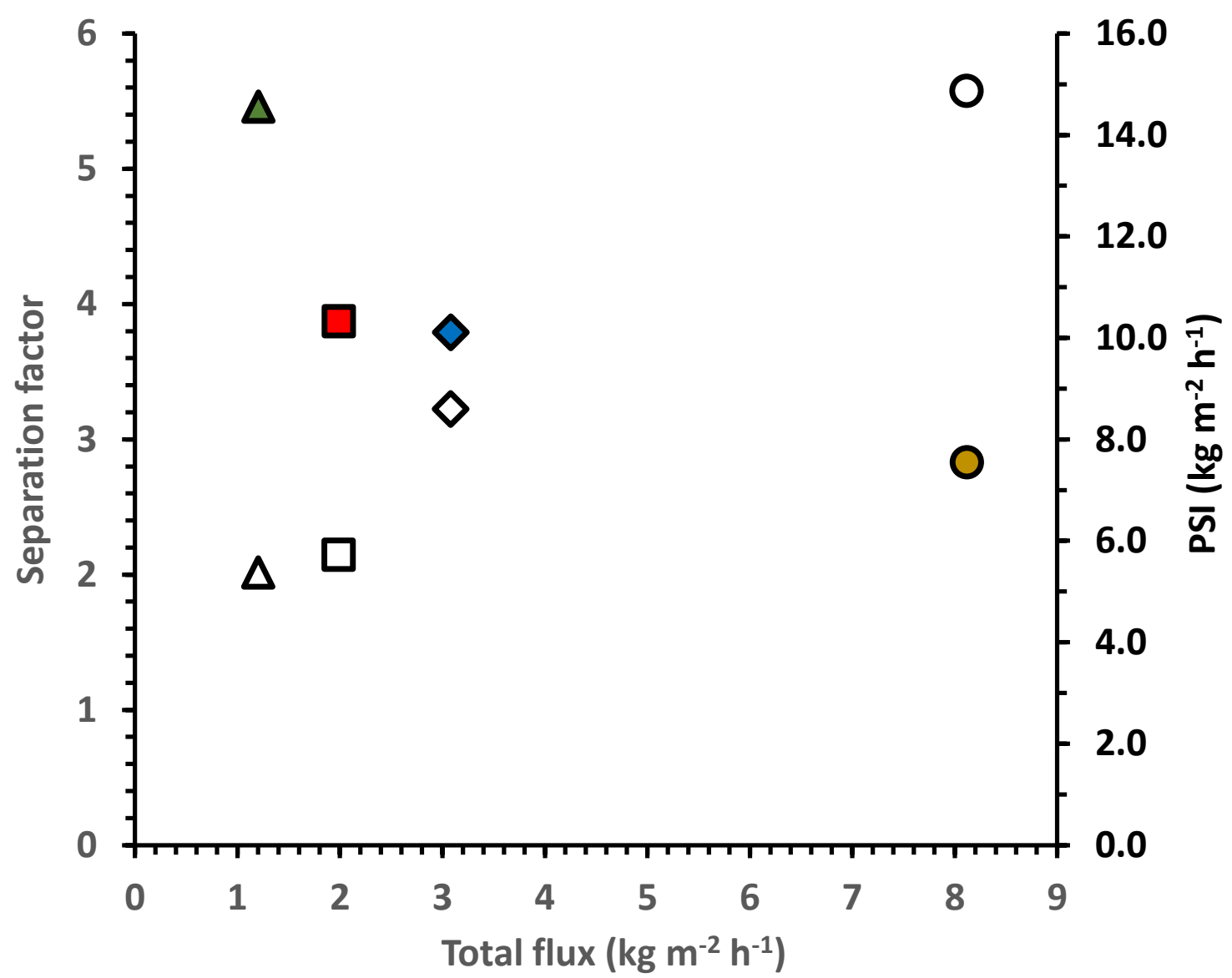

Figure 2. Diagram showing how separation factor (solid symbols, left hand axis) and PSI (open symbols, right hand axis) relate to total flux for PIM-SBF membrane (squares) and mixed matrix membranes of PIM-SBF with 5 wt\% HPB network (triangles), OPQ network (diamonds) and TPB network (circles), for pervaporation at $65^{\circ} \mathrm{C}$ of a toluene/DMSO mixture (77:23 by volume).

MMMs with thicknesses in the range 100-120 $\mu$ m were prepared of PIM-SBF with 5 wt\% of each of the three polyphenylene networks. For comparison, a membrane was prepared without network, but with the same mass of PIM-SBF, for which the thickness was $43 \mu \mathrm{m}$. Figure 2 shows total flux, separation factor and PSI for pervaporation of a toluene/DMSO mixture $\left(77: 23\right.$ volume ratio) at a temperature of $65^{\circ} \mathrm{C}$ with a permeate pressure of 10 mbar. Full results, including fluxes normalized for membrane thickness, are given in the supplementary material (Tables S1 and S2). The PIM-SBF membrane gives a reasonable separation factor of 3.9 with a total flux of $2.0 \mathrm{~kg} \mathrm{~m}^{-2} \mathrm{~h}^{-1}$, which corresponds to a toluene flux of $1.8 \mathrm{~kg} \mathrm{~m}^{-2} \mathrm{~h}^{-1}$. For the networks, there is a trade-off between the highly aromatic character, which is expected to enhance the affinity for toluene and hence the separation factor, and the high porosity (indicated by high apparent surface area) which will increase the fluxes of both components at the expense of separation factor. The addition of $5 \mathrm{wt} \%$ HPB network, which has a lower BET surface area than the other two networks, improves the separation factor to 5.5, with a $35 \%$ loss in total flux. The other two networks give an increase in flux at the expense of separation factor. In terms of PSI, the MMM with TPB gives the best performance. However, other factors also need to be considered for application to a real process, including the ranges of these parameters that are suitable for a particular process. 
Chau et al. ${ }^{17}$ previously investigated the separation of toluene/DMSO mixtures by reverse osmosis, a membrane process in which the feed is pressurized. With a perfluoropolymer membrane they achieved excellent separation, the permeate being pure toluene, but compared to the present work the fluxes were low $\left(<0.2 \mathrm{~kg} \mathrm{~m}^{-2} \mathrm{~h}^{-1}\right.$ for a $75 \mathrm{wt} \%$ toluene feed at a pressure of $\left.3500 \mathrm{kPa}\right)$.

\section{Conclusions}

A spirobifluorene polymer of intrinsic microporosity forms membranes that are stable in a mixture of toluene and DMSO without further crosslinking. In pervaporation, PIM-SBF exhibits selective transport of toluene, making it an excellent candidate as a membrane material for the recovery of aromatic hydrocarbons from polar solvents. The membrane performance may be further enhanced by addition of high surface area hypercrosslinked polyphenylene networks. A network based on hexaphenylbenzene improves the separation factor, while networks based on triphenylbenzene or octaphenylquinquephenyl offer enhanced flux.

\section{Experimental Section}

General. For the synthesis of monomers and polymers, reagents and solvents were acquired from SigmaAldrich, Fluorochem and VWR International.

NMR spectra $\left({ }^{1} \mathrm{H}\right.$ and $\left.{ }^{13} \mathrm{C}\right)$ in $\mathrm{CDCl}_{3}$ were produced on a Varian Inova $400 \mathrm{MHz}$ spectrometer for the networks and on a Bruker Avance AVA $500 \mathrm{MHz}$ spectrometer for PIM-SBF.

FTIR spectra of PIM-SBF were produced using a Perkin-Elmer 1600 FTIR spectrometer (in the range of 4000$500 \mathrm{~cm}^{-1}$ ) with powder samples mounted on a zinc selenium/diamond plate.

Gel permeation chromatography (GPC) was used to determine average-molecular weights of PIM-SBF using a GPC MAX 1000 system equipped with two Viscotek columns (CLM3012 LT 5000L) and a RI detector (VE3580) using $\mathrm{CHCl}_{3}$ solution ( $1 \mathrm{mg} \mathrm{mL}^{-1}$ ) at a flow rate of $1 \mathrm{~mL} \mathrm{~min}{ }^{-1}$.

$\mathrm{N}_{2}$ adsorption/desorption isotherms at $77 \mathrm{~K}$ were determined for networks using a Micromeritics ASAP 2020 Surface Area and Porosity Analyser, samples being first degassed under high vacuum for $12 \mathrm{~h}$ at $120{ }^{\circ} \mathrm{C}$, and for PIM-SBF using a Micromeritics 3Flex surface characterization analyser, the sample being first degassed under high vacuum for $12 \mathrm{~h}$ at $110^{\circ} \mathrm{C}$ then in-situ degassed at $110{ }^{\circ} \mathrm{C}$ for another $12 \mathrm{~h}$ prior to analysis.

Thermogravimetric analysis (TGA) of PIM-SBF was carried out using a Netzsch STA 449 F5 Jupiter thermogravimetric analyser; the sample was heated at a heating rate of $10^{\circ} \mathrm{C} \mathrm{min}^{-1}$ from room temperature to $1000{ }^{\circ} \mathrm{C}$ under a nitrogen atmosphere.

Synthesis of PIM-SBF. 2,2',3,3'-Tetrahydroxy-9,9'-spirobifluorene (5.00 g, $13.14 \mathrm{mmol})$ and 2,3,5,6tetrafluoroterephthalonitrile $(2.63 \mathrm{~g}, 13.14 \mathrm{mmol})$ were dissolved in anhydrous DMF $(66 \mathrm{~mL})$ at $\mathrm{room}$ temperature under nitrogen atmosphere. Anhydrous $\mathrm{K}_{2} \mathrm{CO}_{3}(14.53 \mathrm{~g}, 105.15 \mathrm{mmol})$ was added and the mixture was heated to $65{ }^{\circ} \mathrm{C}$ for $92 \mathrm{~h}$. On cooling, the mixture was poured into water (500 mL), acidified with hydrochloric acid (2M) and filtered off. The precipitate was washed repeatedly with water, acetone and methanol, reprecipitated twice from the mixture of acetone/methanol $(2 / 1,700 \mathrm{~mL})$ to remove oligomers, and subsequently refluxed in methanol overnight to remove traces of residual solvent. The resulting product was collected by filtration and dried under vacuum at $110{ }^{\circ} \mathrm{C}$ for $12 \mathrm{~h}$ to afford the final polymer as a yellow powder $(5.59 \mathrm{~g}, 85 \%) . v_{\max }\left(\mathrm{cm}^{-1}\right)$ : 3060, 2896, 2241, 1601, 1435, 1350, 1269, 1200, 1153, 1103, 1011, 868, 
740; ${ }^{1} \mathrm{H}$ NMR (500 MHz) $\delta 7.75$ (s, 2H), $7.43(\mathrm{~s}, 4 \mathrm{H}), 7.16(\mathrm{~s}, 2 \mathrm{H}), 6.74(\mathrm{~s}, 2 \mathrm{H}), 6.40(\mathrm{~s}, 2 \mathrm{H}) ;{ }^{13} \mathrm{C} \mathrm{NMR}(126 \mathrm{MHz}) \delta$ $146.45,139.40,127.54,120.15,108.35,94.34,65.50 ;$ GPC: $M_{n}=66,500, M_{w}=170,000$. BET surface area $=869$ $\mathrm{m}^{2} \mathrm{~g}^{-1}$; total pore volume $=0.58 \mathrm{~cm}^{3} \mathrm{~g}^{-1}\left(\right.$ at $\left.p / p^{\circ}=0.85\right)$; TGA: The peak degradation temperature of weight loss is $\sim 623^{\circ} \mathrm{C}$.

Synthesis of triphenylbenzene (TPB) network polymer. A solution of 1,3,5-triphenylbenzene (5.00 g, 16.32 $\mathrm{mmol})$ and DCM $(200 \mathrm{~mL})$ was stirred under nitrogen and aluminium trichloride (21.76 g, 163.20 mmol) was added. The solution was then stirred at $50{ }^{\circ} \mathrm{C}$ under nitrogen for $24 \mathrm{~h}$. Upon cooling, the reaction mixture was poured into water and the resulting precipitate collected via filtration. The solid was washed with water, ethanol, chloroform, tetrahydrofuran (THF), acetone and methanol to afford the desired phenylene network polymer as a brown powder $(7.24 \mathrm{~g})$ in $146 \%$ yield based on an ideal structure. BET surface area $=2150 \mathrm{~m}^{2} \mathrm{~g}^{-1}$; total pore volume $=1.28 \mathrm{~cm}^{3} \mathrm{~g}^{-1}\left(\right.$ at $\left.p / p^{\circ}=0.85\right)$.

Synthesis of 2,3,4,5-tetraphenyl-2,4-cyclopentadien-1-one. A solution of 1,3-diphenylpropan-2-one (5.00 g, $23.78 \mathrm{mmol}$ ) and benzil $(5.00 \mathrm{~g}, 23.78 \mathrm{mmol})$ in ethanol $(50 \mathrm{~mL})$ was stirred under nitrogen and potassium hydroxide $(0.34 \mathrm{~g}, 5.95 \mathrm{mmol})$ in ethanol $(5 \mathrm{~mL})$ was added. The solution was then stirred at $85{ }^{\circ} \mathrm{C}$ under nitrogen for $1 \mathrm{~h}$, when potassium hydroxide $(0.34 \mathrm{~g}, 5.95 \mathrm{mmol})$ in ethanol $(5 \mathrm{~mL})$ was added. After heating for a further $1 \mathrm{~h}$ the reaction mixture was filtered hot to collect the resulting precipitate. The solid was washed with water and ethanol to afford 2,3,4,5-tetraphenyl-2,4-cyclopentadien-1-one as a black powder (8.53 g) in 93\% yield. ${ }^{1} \mathrm{H}$ NMR $(400 \mathrm{MHz}) \delta 7.32-7.24(\mathrm{~m}, 12 \mathrm{H}), 7.24-7.18(\mathrm{~m}, 4 \mathrm{H}), 7.00-6.94(\mathrm{~m}, 4 \mathrm{H}) ;{ }^{13} \mathrm{C} \mathrm{NMR}(101$ $\mathrm{MHz}) \delta 200.38,154.51,133.08,130.78,130.18,129.37,128.55,128.07,128.03,127.50,125.34$.

Synthesis of 1,2,3,4,5,6-hexaphenylbenzene (HPB). A solution of 2,3,4,5-tetraphenyl-2,4-cyclopentadien-1one $(5.00 \mathrm{~g}, 13.00 \mathrm{mmol})$ and diphenylacetylene $(3.48 \mathrm{~g}, 19.50 \mathrm{mmol})$ in diphenyl ether $(30 \mathrm{~mL})$ was stirred under nitrogen at $250{ }^{\circ} \mathrm{C}$ for $24 \mathrm{~h}$. Upon cooling, the reaction mixture was poured into methanol where a white precipitate formed. The solid was collected via filtration and washed thoroughly with methanol and then with petroleum ether 40-60 to afford 1,2,3,4,5,6-hexaphenylbenzene as a white solid (6.23 $\mathrm{g}$ ) in $90 \%$ yield. ${ }^{1} \mathrm{H}$ NMR (400 MHz) $\delta 6.85-6.70(\mathrm{~m}, 30 \mathrm{H}) ;{ }^{13} \mathrm{C}$ NMR $(101 \mathrm{MHz}) \delta 140.62,140.30,131.42,126.58,125.19$.

Synthesis of hexaphenylbenzene (HPB) network polymer. A solution of 1,2,3,4,5,6-hexaphenylbenzene (2.00 $\mathrm{g}, 3.74 \mathrm{mmol})$ and $\mathrm{DCM}(100 \mathrm{~mL})$ was stirred under nitrogen and aluminium trichloride $(5.00 \mathrm{~g}, 37.40 \mathrm{mmol})$ was added. The solution was then stirred at $50{ }^{\circ} \mathrm{C}$ under nitrogen for $24 \mathrm{~h}$. Upon cooling, the reaction mixture was poured into water and the resulting precipitate collected via filtration. The solid was washed with water, ethanol, chloroform, THF, acetone and methanol to afford the desired phenylene network polymer as a brown powder $(3.37 \mathrm{~g})$ in $170 \%$ yield based on an ideal structure. BET surface area $=1510 \mathrm{~m}^{2} \mathrm{~g}^{-1}$; total pore volume $=$ $0.78 \mathrm{~cm}^{3} \mathrm{~g}^{-1}$ (at $p / p^{\circ}=0.85$ ).

Synthesis of 3,3'-(1,4-phenylene)bis[2,4,5-triphenyl-2,4-cyclopentadien-1-one. A solution of 1,3diphenylpropan-2-one $(6.14 \mathrm{~g}, 29.28 \mathrm{mmol})$ and bisbenzil $(5.00 \mathrm{~g}, 23.78 \mathrm{mmol})$ in ethanol $(50 \mathrm{~mL})$ was stirred under nitrogen and potassium hydroxide $(0.20 \mathrm{~g}, 3.65 \mathrm{mmol})$ in ethanol $(5 \mathrm{~mL})$ was added. The solution was then stirred at $85{ }^{\circ} \mathrm{C}$ under nitrogen for $1 \mathrm{~h}$, when potassium hydroxide $(0.20 \mathrm{~g}, 3.65 \mathrm{mmol})$ in ethanol $(5 \mathrm{~mL})$ was added. After heating for a further $1 \mathrm{~h}$ the reaction mixture was filtered hot to collect the resulting precipitate. The solid was washed with water and ethanol to afford 3,3'-(1,4-phenylene)bis[2,4,5-triphenyl2,4-cyclopentadien-1-one as a black powder $(9.54 \mathrm{~g})$ in $58 \%$ yield. ${ }^{1} \mathrm{H} \mathrm{NMR}(400 \mathrm{MHz}) \delta 7.21-7.07(\mathrm{~m}, 30 \mathrm{H})$, 6.84 (d, J = 7.5 Hz, 4H); ${ }^{13} \mathrm{C}$ NMR $(101 \mathrm{MHz}) \delta 200.11,154.09,153.90,133.49,132.87,130.57,130.51,130.11$, $130.05,129.26,129.05,128.59,128.09,128.01,127.92,127.63,127.59,125.54,125.25,114.05$.

Synthesis of 3',3'",4',4'",5',5'",6',6"'-octaphenyl-1,1':2',1":4",1'":2"',1'"'-quinquephenyl (OPQ). A solution of 3,3'-(1,4-phenylene)bis[2,4,5-triphenyl-2,4-cyclopentadien-1-one (5.00 g, $7.24 \mathrm{mmol}$ ) and diphenylacetylene $(3.87 \mathrm{~g}, 21.72 \mathrm{mmol})$ in diphenylether $(30 \mathrm{~mL})$ was stirred under nitrogen at $250{ }^{\circ} \mathrm{C}$ for $24 \mathrm{~h}$. Upon cooling, the 
reaction mixture was poured into methanol where a white precipitate formed. The solid was collected via filtration and washed thoroughly with methanol and then with petroleum ether 40-60 to afford 3',3'", 4',4'",5',5'",6',6"'-octaphenyl-1,1':2',1":4"',1"':2'"',1"'"-quinquephenyl as a white solid (4.70 g) in $66 \%$ yield. ${ }^{1} \mathrm{H}$ NMR $(400 \mathrm{MHz}) \delta 7.29-7.22(\mathrm{~m}, 5 \mathrm{H}), 7.05-6.99(\mathrm{~m}, 4 \mathrm{H}), 6.96-6.91(\mathrm{~m}, 5 \mathrm{H}), 6.84-6.79(\mathrm{~m}, 10 \mathrm{H})$, $6.79-6.70(\mathrm{~m}, 15 \mathrm{H}), 6.67-6.63(\mathrm{~m}, 10 \mathrm{H}), 6.61-6.57(\mathrm{~m}, 5 \mathrm{H}) ;{ }^{13} \mathrm{C} \mathrm{NMR}(101 \mathrm{MHz}) \delta 140.75,131.75,131.46$, $131.36,129.75,126.56,126.50,125.06,118.90,112.13$.

Synthesis of octaphenylquinquephenyl (OPQ) network polymer. A solution of 3',3'",4',4'",5',5'"',6',6'"'octaphenyl-1,1':2',1":4",1"':2'"',1"'"-quinquephenyl (2.00 g, $2.02 \mathrm{mmol})$ and DCM (100 mL) was stirred under nitrogen and aluminium trichloride $(5.00 \mathrm{~g}, 20.20 \mathrm{mmol})$ was added. The solution was then stirred at $50{ }^{\circ} \mathrm{C}$ under nitrogen for $24 \mathrm{~h}$. Upon cooling, the reaction mixture was poured into water and the resulting precipitate collected via filtration. The solid was washed with water, ethanol, chloroform, THF, acetone and methanol to afford the desired phenylene network polymer as a brown powder $(2.91 \mathrm{~g})$ in $147 \%$ yield based on an ideal structure. BET surface area $=2140 \mathrm{~m}^{2} \mathrm{~g}^{-1}$; total pore volume $=1.40 \mathrm{~cm}^{3} \mathrm{~g}^{-1}\left(\right.$ at $\left.p / p^{0}=0.85\right)$.

Membrane preparation. Self-standing PIM-SBF polymer membranes were prepared by dissolving $0.200 \mathrm{~g}$ of powdered polymer in $10 \mathrm{~mL}$ of chloroform, large particulates were removed via filtration through glass wool before pouring the solution into a Teflon dish and allowing the membrane to form via slow evaporation over $72 \mathrm{~h}$. In the case of the MMMs, $5 \mathrm{wt} \%$ of the polyphenyl network was added to the fully solubilised polymer solution prior to pouring into the Teflon dish and the resulting solution mixed via sonication for 30 min.

Pervaporation. An in-house batch pervaporation system was used for all experiments. A circular disk of polymer (diameter $2.50 \mathrm{~cm}$ ) was cut from a membrane sheet, fixed in the membrane cell and sealed with a Viton O-ring (internal diameter $1.95 \mathrm{~cm}$ ). Subsequently, a toluene/DMSO (77:23 volume ratio) feed solution was prepared and kept at a constant temperature by heating with a water bath. Experiments were carried out at $65{ }^{\circ} \mathrm{C}$. The pervaporation was operated using vacuum as driving force, keeping the pressure on the permeate side at 10 mbar. The permeate vapour was cooled by liquid nitrogen and collected in a trap. The pervaporation was run for $2 \mathrm{~h}$. The resulting permeate was diluted with dichloromethane and the concentration determined by gas chromatography. Analysis was performed using an Agilent 7820A gas chromatography system with a flame ionization detector. The concentration of toluene and DMSO in the diluted sample was determined from the area of the peaks using calibration lines from measurements of toluene and DMSO solutions of known concentrations. The composition of the original sample was then calculated on the basis of the known dilution. The column was a Phenomenex, ZB-SemiVolatiles Guardian 30 $\mathrm{m} \times 0.25 \mathrm{~mm} \times 0.25 \mu \mathrm{m}$. Helium was used as carrier gas with a constant flow rate of $1.2 \mathrm{~mL} \mathrm{~min}^{-1}$. The ion source was set at a temperature of $190{ }^{\circ} \mathrm{C}$. The oven temperature programming was initially $70{ }^{\circ} \mathrm{C}$, ramped at $10^{\circ} \mathrm{C} \mathrm{min}-1$ up to $250{ }^{\circ} \mathrm{C}$, and isothermal again at this temperature for $5 \mathrm{~min}$. The injection volume was $2 \mu \mathrm{L}$, applying a split ratio of 60:1. The scanning time was $21 \mathrm{~min}$.

\section{Acknowledgements}

This work was supported by an Institutional Links grant, No. 351983438, funded by the British Council and by the Ministry of Science and Higher Education of The Russian Federation, project 14.616.21.0100 "Development of a membrane method for the recovery of aromatic hydrocarbons from their mixtures with polar solvents". 


\section{Supplementary Material}

Nitrogen adsorption/desorption isotherms at $77 \mathrm{~K}$ and tabulated pervaporation results can be found in the supplementary material file.

\section{References}

1. Budd, P. M.; Ghanem, B. S.; Makhseed, S.; McKeown, N. B.; Msayib, K.J.; Tattershall, C. E. Chem. Commun. 2004, 230-231.

https://doi.org/10.1039/B311764B

2. McKeown, N.B. Polymer 2020, 202, 122736.

https://doi.org/10.1016/i.polymer.2020.122736

3. Budd, P.M. In Sustainable Nanoscale Engineering; Szekely, G.; Livingston, A.G. Eds.; Elsevier: Amsterdam, 2020; ch. 9, pp 231-264.

https://doi.org/10.1016/B978-0-12-814681-1.00009-6

4. Budd, P. M.; Elabas, E. S.; Ghanem, B. S.; Makhseed, S.; McKeown, N. B.; Msayib, K.J.; Tattershall, C. E.; Wang, D. Adv. Mater. 2004, 16, 456-459.

https://doi.org/10.1002/adma.200306053

5. Kirk, R. A.; Putintseva, M.; Volkov A.; Budd P. M., BMC Chem. Eng. 2019, 1, article 18. https://doi.org/10.1186/s42480-019-0018-4

6. Podtynnikov, I. A.; Balynin, A. V.; Yushkin, A. A.; Budd, P. M.; Volkov, A. V.; Borisov, I. L. Key Eng. Mater. 2020, 869, 408-412.

https://doi.org/10.4028/www.scientific.net/KEM.869.408

7. Yushkin, A. A.; Balynin, A. V.; Bakhtin, D. S.; Kirk, R.; Budd, P. M.; Volkov, A. V. Key Eng. Mater. 2020, 869, 431-436.

https://doi.org/10.4028/www.scientific.net/KEM.869.431

8. Putintseva, M. N.; Yushkin, A. A.; Bondarenko, G. N.; Kirk, R. A.; Budd, P. M.; Volkov, A. V. Pol. Sci. Ser. B, 2019, 61, 795-805.

https://doi.org/10.1134/S1560090419060113

9. Bezzu, C. G.; Carta, M.; Tonkins, A.; Jansen, J. C.; Bernardo, P.; Bazzarelli, F.; McKeown, N. B., Adv. Mater. 2012, 24, 5930-5933.

https:/doi.org/10.1002/adma.201202393

10. Bezzu, C.G.; Carta, M.; Ferrari, M.-C.; Jansen, J.C.; Monteleone, M.; Esposito, E.; Fuoco, A.; Hart, K.; LiyanaArachchi, T.P.; Colina, C.M.; McKeown, N.B. J. Mater. Chem. A, 2018, 6, 10507-10514.

https:/doi.org/10.1039/c8ta02601g

11. Al-Hetlani, E.; Amin, M.O.; Bezzu, C.G.; Carta, M., R. Soc. Open Sci. 2020, 7, 200741

https:/doi.org/10.1098/rsos.200741

12. Msayib, K.J.; McKeown, N.B. J. Mater. Chem. A 2016, 4, 10110-10113.

https://doi.org/10.1039/c6ta03257e

13. Sing, K.S.W.; Everett, D.H.; Haul, R.A.W.; Moscou, L.; Pierotti, R.A.; Rouquerol J; Siemieniewska, T. Pure Appl. Chem. 1985, 57, 603-19.

https://doi.org/10.1351/pac198557040603

14. Fieser, L.F. Org. Synth. 1966, 46, 44. 
https:/doi.org/10.15227/orgsyn.046.0044

15. Ogliaruso, M.A.; Becker, E.I. J. Org. Chem., 1965, 30, 3354-3360.

https://doi.org/10.1021/jo01021a022

16. Carta, M.; Bernardo, P.; Clarizia, G.; Jansen, J.C.; McKeown, N.B., Macromolecules 2014, 47, 8320-8327. https://doi.org/10.1021/ma501925j

17. Chau, J.; Basak, P.; Sirkar, K.K., J. Membr. Sci. 2018, 563, 541-551.

https://doi.org/10.1016/i.memsci.2018.05.076

This paper is an open access article distributed under the terms of the Creative Commons Attribution (CC BY) license (http://creativecommons.org/licenses/by/4.0/) 